\title{
Comparison of Relationship between Solubilization and Methane Productivity on Anaerobic Digestion of Pre-treated Waste Activated Sludge
}

\author{
Byung-Kyu Ahn $^{1 \oplus} \cdot{\text { Tae-Hoon } \mathrm{Kim}^{1}{ }^{\oplus} \cdot \text { Hyojeon } \mathrm{Kim}^{2} \odot \cdot \text { Seoktae Kang }}^{2} \cdot$ Yeo-Myeong Yun $^{1+\odot}$ \\ ${ }^{1}$ Department of Environmental Engineering, Chungbuk National University, Republic of Korea \\ ${ }^{2}$ Department of Civil and Environmental Engineering, KAIST, Republic of Korea
}

(Received October 19, 2022; Revised January 13, 2022; Accepted February 8, 2022)

Objectives: Various pre-treatment methods have been applied to waste activated sludge(WAS) to improve the efficiency of anaerobic digestion(AD) by enhancing hydrolysis. The objective of this study was to find out the relationship between increased solubilization and $\mathrm{AD}$ efficiency in response to the application of different pretreatment methods(Acid+Heat and Alkali+Heat) to WAS.

Methods: Acid $+\operatorname{Heat}\left(\mathrm{pH} 2+130^{\circ} \mathrm{C}\right)$ and Alkali+Heat $\left(\mathrm{pH} 10+130^{\circ} \mathrm{C}\right)$ pretreatment processes were performed by adding $\mathrm{HCl}$ and $\mathrm{KOH}$, respectively. A biochemical methane potential(BMP) test was subsequently conducted to determine the AD efficiency of pretreated WAS. Finally, the physicochemical characteristics in the effluent of AD of WAS, done by excitation-emission matrix(EEM) and size exclusion chromatography(SEC), were analyzed to investigate the degree of changed intermediates during microbial degradation of organic compounds.

Results: Both Acid+Heat and Alkali+Heat pretreatments resulted in similar solubilization of WAS, reaching 34.1 and $36.3 \%$, respectively. Meanwhile, it was found that the $\mathrm{CH} 4$ yield obtained from the Alkali+Heat pretreated sample was lower than the sample of Acid+Heat. The results of EEM analysis showed that the Alkali+Heat pretreated WAS had a higher portion of less biodegradable organic compounds with high- molecular weight in the soluble sample than that of the Alkali+Heat pretreated sample.

Conclusion: This study was conducted to clarify the relationship by comparing the hydrolysis rate and AD efficiency according to the application of Acid+Heat and Alkali+Heat pretreatment. It was found that the amount of methane generated could vary depending on the properties of the dissolved substances in response to different pretreatment approaches.

Keywords: Anaerobic digestion, $\mathrm{CH}_{4}$ production, pretreatment, solubilization, soluble matter 


\title{
연구논문
}

\section{하수잉여찌꺼기의 전처리 적용에 따른 바이오가스 생산 효율과 가용화물질의 관계 비교}

\author{
안병규 $^{1 \oplus} \cdot$ 김태훈 $^{1 \odot} \cdot$ 김효전 $^{2} \cdot$ 강석태 $^{\circledR 2} \cdot$ 윤여명 $^{\circledR 1^{+}}$ \\ '충북대학교 환경공학과 \\ 2한국과학기술원 건설 및 환경공학과
}

목적 : 하수잉여찌꺼기의 혐기성 소화 시 바이오가스 생산 효율 증가를 위해 다양한 물리화학적 방법을 적용한 전처리를 적용하고 있다. 본 연구에서는 하수잉여찌꺼기의 Acid+Heat 및 Alkali+Heat 전처리에 따른 가용화율 증가와 생산된 메탄량의 변화 비교를 통해 전처리 방법 차이에 따른 관계 규명을 목적으로 했다.

방법: 하수잉여찌꺼기에 Acid+Heat과 Alkali+Heat 전처리를 각각 적용했다. Acid+Heat 전처리의 경우 $3 \mathrm{~N} \mathrm{HCl}$ 를 주입하 여 $\mathrm{pH} 2$ 로 고정했으며 Alkali+Heat 전처리는 $3 \mathrm{~N} \mathrm{KOH}$ 를 이용하여 $\mathrm{pH}$ 를 10 으로 조절 후 130 도에서 30 분간 열처리를 적용했다. 전처리 전후 $\mathrm{SCOD}$ 분석을 통해 가용화율을 측정했으며 BMP test(Biochemical Methane Potential test)를 통해 메탄발생량을 측정했다. 전처리 시 용존성 물질의 성상 변화를 확인하기 위해 High-performance size-exclusion chromatography(HPLC-SEC, LC-20A series, Shimadzu, Japan)및 Fluorescence excitation-emission matrix(FEEM, RF6000 를 통해 분자량분석과 FEEM 분석을 수행했다.

결과 및 토의: 전처리 적용에 따른 가용화율 분석 결과 Alkali+Heat과 Acid+Heat 전처리 샘플에서 각각 $36.3 \%$, $34.1 \%$ 로 비슷한 결과를 보였다. 그러나 Biochemical methane potential(BMP) test 수행을 통한 메탄 생산 비교 결과 Alkali+Heat 전처리한 샘플과 비교하여 Acid + Heat 전처리 샘플에서 약 $26 \%$ 높은 수준으로 나타났다. 전처리 방법 에 따른 가용화율과 메탄생산량의 차이의 원인 규명을 위해 가용화된 물질을 대상으로 FEEM 분석 및 분자량 분 석을 수행했다. 그 결과 Acid+Heat 전처리의 적용을 한 기질 내 고분자 고형물질을 혐기성 미생물이 가용할 수 있 는 수준의 저분자 형태의 용존 유기물로의 효과적인 분해를 이룬 것으로 나타났다. 반면 Alkali+Heat 전처리를 적 용한 기질의 용존 유기물에서 상대적으로 높은 수준의 고분자 형태 및 방향족 계열의 물질이 포함되어 있었음을 확인했다. 이는 전처리를 통해 기질의 가용화는 증가되었으나 미생물이 흡수할 수 있는 형태의 저분자 물질로의 분해가 이루어지지 않아 상대적으로 낮은 수준의 메탄 생산의 결과로 이어진 것으로 나타났다.

결론 : 실험은 Acid+Heat과 Alkali+Heat 전처리 적용에 따른 가수분해율과 메탄발생량을 비교함으로써 그 관계규명 을 목적으로 진행되었다. 실험결과 전처리를 통해 가수분해율이 증가된다 하더라도 포함된 용존성 물질의 성상에 따라 메탄발생량이 달라질 수 있음을 확인했다. 즉, 전처리에 따른 가용화율의 변화는 메탄생산성과 연계할 수 있 는 전처리 효과로 판단하는 절대 지표가 아닐 수 있다는 것을 시사한다.

Keywords : 가용화율, 용존성 유기물질, 전처리, 하수잉여슬러지, 혐기성 소화

\section{1. 서 론}

세계적으로 인구증가와 더불어 도시화 발달에 의한 하수관 보급 및 하수처리 시설의 확대가 가속화되고 있다. 한국의 경우 하수도 보급률의 증가에 따라 2019년 일일 유입 하수량 $20,906,964 \mathrm{~m}^{3} / \mathrm{d}$ 을 처리하기 위해 671 개의 공공하수처리장 $\left(500 \mathrm{~m}^{3} /\right.$ 일 이상)이 가동되고 있으며 이 중 대부분의 시설은 전통방식인 활성슬러지 공법을 적용하고 있다. ${ }^{1)}$ 활성슬러지 공법은 운영관리비의 약 $20 \%$ 를 전력비에 포함하며 이는 국내
전체 전력소비량의 약 $0.5 \%$ 를 차지하기에 공공하수처리시설은 에너지 다소비시설로 분류되고 있다. 따라서 환경부에서는 공공 하수처리장을 에너지 자립 시설로 개선하기 위해 Water-Energy Nexus 확립을 위한 노력을 계속하고 있달.

하수처리장의 Water-Energy Nexus 확립을 위해 다양한 방 법의 접근이 이루어지고 있으며 그 중 하수찌꺼기의 처리와 동시에 화석연료를 대체할 수 있는 에너지원인 메탄의 생산 이 가능한 혐기성 소화 기술의 적용이 대표적이다. 혐기성소 화는 다양한 유기성폐기물을 기질로 하여 4 단계의 생물학적 
반응(가수분해, 산 생성, 아세트산 생성, 메탄 생성)을 거쳐 최종적으로 메탄가스를 포함한 바이오가스를 생산하는 기술 이다. ${ }^{3)}$ 혐기성소화의 기질로 이용되는 하수 찌꺼기는 비교적 생분해 가능한 물질의 함량이 높은 1 차 찌꺼기(Primary sludge)와 대부분 미생물로 구성된 잉여찌꺼기(Waste activated sludge, WAS)로 구분된다. ${ }^{4)}$ 잉여찌꺼기의 경우 미생물의 세 포벽 등 안정한 구조에 의해 혐기성 소화 과정 중 가수분해가 혐기성소화 전체 공정효율을 좌우하는 율속단계(Rate-limiting step)로 작용된다. ${ }^{5)}$ 잉여 찌꺼기의 혐기성 소화 시 가수분해 반응을 촉진 및 메탄생산량의 증가를 위해 소화조에 유입하 기 전 물리-화학적, 열, 생물학적 방법 등의 다양한 전처리 기 술을 적용하는 것이 일반적이며 현장에서는 전처리 효율, 설 치\&운영비용 등을 종합적으로 고려한 최적의 전처리의 기술 을 채택하고 있다. ${ }^{6}$ 추가로 화학물질 주입과 동시에 열처리를 하는 열화학적 전처리, 그 중 산+열 전처리(Acid+heat pre-treatment, Acid+Heat) 및 알칼리+열 전처리(Alkali+heat pre-treatment, Alkali+Heat)는 적용이 간단하며 높은 효율을 보인다고 알려져 있다. ${ }^{7-11)}$

전처리 효율을 평가하기 위해 대상 물질의 총 바이오매스 양 대비 전처리에 따라 증가된 가용화 바이오매스 양을 비교 하는 가용화율(Solubilization, \%)이 지표로 쓰인다. 일반적으 로 전처리에 의한 가용화율의 증가와 에너지 소모 증가는 서 로 비례적인 관계를 가지고 있으며 가용화율의 증가는 바이 오가스 생산효율 향상의 결과로 이어진다는 연구결과가 대부 분이다. ${ }^{12,13)}$ 그러나 실제 가용화율의 증가와 바이오가스 생 산효율 향상의 관계가 항상 비례적이지 않으며 그 상관관계 에 대한 의문이 지속적으로 제기되고 있다. ${ }^{14)}$ 논문에서는 전 처리를 통해 가수분해율이 증가되더라도 최종적으로 메탄생 산율은 증가하지 않음을 설명했다. 또한, 전처리에 의해 증가 된 가용화물 중 생물학적으로 분해가 되지 않는 물질이 상당 수 포함하고 있다는 연구도 보고되었다. ${ }^{15-17)}$ 그러므로 전처 리 방법에 따른 가용화 효율 및 메탄 생산에 대한 관계에 대 한 정확한 규명이 필요하나 관련 연구가 활발히 이루어지지 않고 있다.

따라서 본 연구에서는 하수잉여찌꺼기의 전처리 적용에 따 른 가용화 및 바이오가스 전환율의 비교를 통해 둘의 관계를 명확히 하는 것을 목적으로 진행됐다. 본 연구의 목적 달성을 위해 잉여찌꺼기의 전처리 방법은 대표적인 전처리 방법 중 $\mathrm{Lab}$ 에서 수행하기 용이한 Acid+Heat 전처리와 Alkali+Heat 전처리를 선택 적용했으며 전처리 후 가용화율과 메탄생성율 의 비교를 수행했다. 또한 가용화된 물질의 성상을 확인하기 위하여 Fluorescence extraction-emission matrix(FEEM)와 분 자량 분석을 추가적으로 수행하였으며 전처리 적용에 따라 증가된 용존 유기물의 특성의 비교분석과 메탄 생산량과 연계 하여 상관관계를 규명하였다.

\section{2. 실험 방법}

\section{1. 기질 및 식종슬러지}

기질은 대전 공공하수처리장에서 발생되는 잉여농축찌꺼기 를 사용했으며 TCOD, SCOD, TS 및 VS는 각각 $55.0 \mathrm{~g} / \mathrm{L}, 3.8$ $\mathrm{g} / \mathrm{L}, 46.1 \mathrm{~g} / \mathrm{L}, 38.8 \mathrm{~g} / \mathrm{L}$ 였다. 식종슬러지는 국내 C 맥주공장 의 폐수처리장 내 혐기성 소화조의 그래뉼 슬러지를 이용했으 며 그 TCOD, SCOD, TS 및 VS는 각각 $124 \mathrm{~g} / \mathrm{L}, 29.5 \mathrm{~g} / \mathrm{L}$, $111.6 \mathrm{~g} / \mathrm{L}, 102.3 \mathrm{~g} / \mathrm{L}$ 였다.

\section{2. 전처리}

잉여찌꺼기의 전처리를 위해 Acid+Heat과 Alkali+Heat 전 처리를 각각 적용했다. Acid+Heat 전처리의 경우 $3 \mathrm{~N} \mathrm{HCl}$ 를 주입하여 $\mathrm{pH}$ 2로 고정했으며 Alkali+Heat 전처리는 $3 \mathrm{~N} \mathrm{KOH}$ 를 이용하여 $\mathrm{pH}$ 를 10 으로 맞추었다. 이후 교반기(SI-600R, JEIO TECH, South Korea)를 이용 약 2시간 동안 교반한 후 Autoclave(Bio Medic, South Korea)를 이용해 $130^{\circ} \mathrm{C}$ 에서 30 분간 열처리를 적용하여 전처리를 진행했다. 전처리 후에는 기질의 변성을 방지하기 위해 냉장보관 $\left(4^{\circ} \mathrm{C}\right)$ 했다.

\subsection{BMP test}

BMP(biochemical methane potential) test는 $250 \mathrm{~mL}$ Serum bottle을 이용 Working volume을 $100 \mathrm{~mL}$ 로 하여 진행하였다. 대조군(None), Acid+Heat, Alkali+Heat 모두 $22 \mathrm{~g} \mathrm{TCOD} / \mathrm{L}$ 의 농도로 주입했으며 식종슬러지는 Working volume의 $30 \%$ 인 $30 \mathrm{~mL}$ 주입하였다. 초기 $\mathrm{pH}$ 는 $3 \mathrm{~N} \mathrm{HCl}$ 및 $3 \mathrm{~N} \mathrm{KOH}$ 를 통해 7.5로 조절했으며 반응조 내 혐기성 상태를 유지하기 위해 $99.9999 \%$ 질소가스를 3분간 Purging한 후 밀봉하여 Shaking incubator(LSI-1005R, DAIHAN LABTECH, Korea)에서 150 $\mathrm{rpm}$ 으로 하여 $38^{\circ} \mathrm{C}$ 의 온도에서 30 일간 batch test를 진행했다.

\section{4. 데이터 분석 및 계산 방법}

TCOD 및 SCOD는 Standard method ${ }^{18)}$ 의 Closed reflux, Colorimetric method을 참고하여 측정했으며 그 중 SCOD는 원심분리기(FLETA-5, Hanil, South Korea)를 통해 716 xg로 20 분간 원심분리 후 상등액을 Syringe filter $(0.45 \mu \mathrm{m}$ pore size, Adventec)에 여과하여 여과된 액체의 $\mathrm{COD}$ 를 측정했다. $\mathrm{pH}$ 는 $\mathrm{pH}$ probe(Vernier $\mathrm{pH}$ sensor)가 부착된 $\mathrm{pH}$ 측정기(Vernier, model LQ2-LE, China)를 통해 측정했다. 발생된 가스 중 메탄 의 함량은 열전도 검출기(Thermal conductivity detector, TCD) 가 부착된 Gas chromatograph(SRI 310, SRI Instrument)를 통 해 분석했다. 사용된 Column은 HayeSep T(3 ft x 1/8")였으며 이동상은 고순도 질소가스(99.9999\%)를 $10 \mathrm{~mL} / \mathrm{min}$ 의 유속으 로 사용했다. DOC 분석은 시료를 Syringe filter(0.45 $\mu \mathrm{m}$ pore size, Adventec)에 여과한 후 TOC analyzer(TOC-L, Shimadzu, 
Japan)를 통해 분석했다. 분자량 분석은 DOC 농도 $20 \mathrm{mg} / \mathrm{L}$ 를 기준으로 하여 UV detector가 부착된 High-performance size-exclusion chromatography(HPLC-SEC, LC-20A series, Shimadzu, Japan)를 통해 분석했다. FEEM분석은 Fluorescence excitation-emission matrix(FEEM, RF6000, Shimadzu, Japan)를 통해 $1 \mathrm{mg} / \mathrm{L}$ 의 DOC를 기준으로 진행되 었으며 Emission wavelength(em)를 $220 \mathrm{~nm}$ 에서 $400 \mathrm{~nm}$ 의 파 장까지 $5 \mathrm{~nm}$ 간격으로 설정, Excitation wavelength(ex)는 250 $\mathrm{nm}$ 에서 $600 \mathrm{~nm}$ 의 파장 구간을 $1 \mathrm{~nm}$ 간격으로 설정하여 분석 을 실시했다.

메탄발생 수율과 메탄발생 속도는 Gompertz model(식 1)을 통해 계산되었다. ${ }^{19)}$

$$
M(t)=M_{o} \times \exp \left\{-\exp \left[\frac{R_{o} \times e}{M_{o}} \times(\lambda-\mathrm{t})+1\right]\right\}
$$

$\mathrm{M}(\mathrm{t})=$ Cumulative $\mathrm{CH}_{4}$ production at cultivation time $(\mathrm{t})(\mathrm{mL})$, $\mathrm{M}_{\mathrm{o}}=\mathrm{CH}_{4}$ production potential $(\mathrm{mL}), \mathrm{R}_{\mathrm{o}}=\mathrm{CH}_{4}$ production rate $(\mathrm{mL} / \mathrm{d}), \lambda=\operatorname{Lag} \operatorname{period}(\mathrm{d}), \mathrm{e}=2.71828$

\section{가용화율은 식 2을 통해 계산했다. ${ }^{20)}$}

$$
\text { Solubilization(\%) }=\frac{S C O D_{\text {after }}-S C O D_{\text {before }}}{\text { TCOD }_{\text {before }}-S C O D_{\text {before }}} \times 100 \%
$$

$$
\begin{aligned}
& \mathrm{SCOD}_{\text {before }}=\text { 전처리 전 } \mathrm{SCOD}(\mathrm{mg} \mathrm{COD} / \mathrm{L}) \\
& \mathrm{SCOD}_{\text {after }}=\text { 전처리 후 } \mathrm{SCOD}(\mathrm{mg} \mathrm{COD} / \mathrm{L}) \\
& \mathrm{TCOD}_{\text {before }}=\text { 전처리 전 } \mathrm{TCOD}(\mathrm{mg} \mathrm{COD} / \mathrm{L})
\end{aligned}
$$

\section{3. 결과 및 고찰}

\section{1. 전처리 적용에 따른 가용화}

Table 1 에서 나타낸 바와 같이 기질의 SCOD는 대조군에 비해 전처리를 적용한 Acid+Heat, Alkali+Heat에서 증가했음을 보였다. 특히 Alkali+Heat 전처리를 적용한 샘플에선 23,500 $\pm 3,345 \mathrm{mg} / \mathrm{L}$ 의 가장 높은 $\mathrm{SCOD}$ 농도가 측정되었다. 반면 Acid+Heat 전처리를 적용한 샘플의 SCOD 농도는 22,310 $\pm 1,155 \mathrm{mg} / \mathrm{L}$ 로 상대적으로 낮게 측정됐다. 해당 $\mathrm{SCOD}$ 값을 이용 가용화율을 계산한 결과 Alkali+Heat과 Acid+Heat에서
각각 $36.6 \%$ 및 $34.1 \%$ 로 나타났다. 즉, Alkali+Heat 전처리 적 용에 비해 Acid+Heat 전처리 적용이 약 $2.2 \%$ 낮은 가용화율 을 보여주지만 측정된 SCOD의 표준편차를 고려할 때 Alkali+ Heat 전처리와 Acid+Heat 전처리의 가용화율은 큰 차이가 없 음을 확인했다.

\section{2. 메탄 생산}

전처리 유무에 따른 BMP test 결과는 Table 1과 Fig.1에 나타냈다. 대조군에 비해 두 전처리 방법 적용에 따른 메탄발 생 수율 및 메탄발생 속도가 증가됨을 확인할 수 있었다. 메탄 수율은 대조군, Acid+Heat, Alkali+Heat에서 91.1 $\pm 0.6,165.8 \pm$ 18.2, $137.2 \pm 2.7 \mathrm{~mL} \mathrm{CH}_{4} / \mathrm{g} \mathrm{COD}$ 로 나타났으며 메탄생산 속도 는 대조군, Acid+Heat, Alkali+Heat 샘플에서 각각 21.4 \pm 0.5 , $39.1 \pm 3.9,27.6 \pm 0.7 \mathrm{~mL} \mathrm{CH} / \mathrm{d}$ 로 측정되었다. Acid+Heat와 Alkali+Heat 전처리에 따른 메탄 생산효율을 비교해본 결과 Acid+Heat가 Alkali+Heat보다 메탄 수율 측면에서 약 1.2배, 메탄발생 속도 측면에서 약 1.4 배 더 높은 것을 확인했다. 본 결과를 통해 Acid+Heat 전처리를 잉여찌꺼기에 적용할 경우 Alkali+Heat 전처리 적용에 비해 더 높은 혐기성 소화 효율을 얻을 수 있을 것이라 판단된다. 일반적으로 알칼리 전처리는 $\mathrm{NaOH}$ 와 $\mathrm{KOH}$ 의 주입을 통한 $\mathrm{pH}$ 상승(12 13) 방법이 대부분 적용되었으나 기질 내 $\mathrm{Na}^{+}$및 $\mathrm{K}^{+}$이온이 과량 존재하여 혐기성 소화 효율 향상에 부정적 영향을 끼칠 수 있다고 보고되고 있다. ${ }^{12,21)}$ 본 연구에서는 Alkali+Heat 전처리 $\mathrm{pH}$ 범위를 10 으

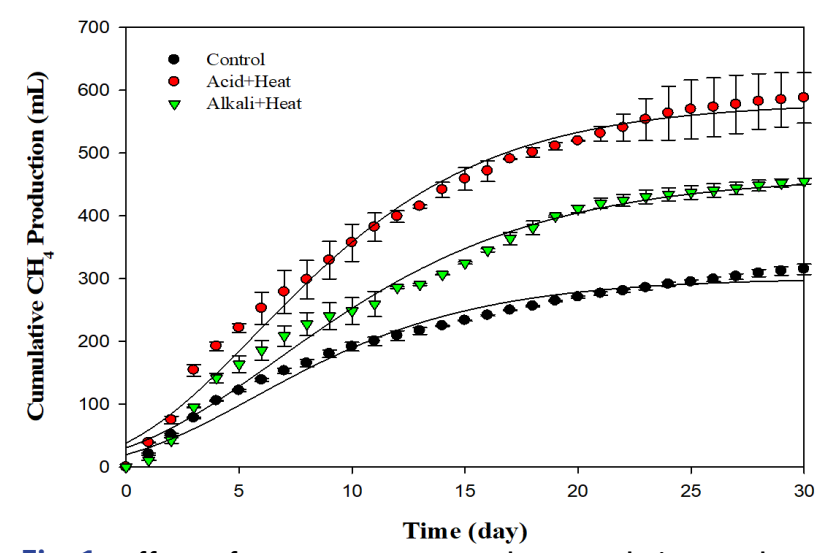

Fig. 1. Effect of pretreatments on the cumulative methane production of waste activated sludge.

Table 1. Experimental results of pretreatment and methane production of waste activated sludge.

\begin{tabular}{cccc} 
& \multicolumn{3}{c}{ Samples } \\
\cline { 2 - 4 } & Control & Acid+Heat(pH $\left.2+130^{\circ} \mathrm{C}\right)$ & Alkali+Heat(pH 10+130 $\left.{ }^{\circ} \mathrm{C}\right)$ \\
\hline SColubilization $(\%)$ & $3,550 \pm 577$ & $22,310 \pm 1,155$ & $23,500 \pm 3,345$ \\
\hline $\mathrm{CH}_{4}$ yield $(\mathrm{mL} \mathrm{CH} / \mathrm{g} \mathrm{COD})$ & - & 34.1 & 36.3 \\
\hline $\mathrm{CH}_{4}$ production rate $(\mathrm{mL} \mathrm{CH} / \mathrm{d})$ & $91.1 \pm 0.6$ & $165.8 \pm 18.2$ & $137.2 \pm 2.7$ \\
\hline Average molecular weight of SCOD $(\mathrm{Da})$ & $21.4 \pm 0.5$ & $39.1 \pm 3.9$ & $27.6 \pm 0.7$ \\
\hline
\end{tabular}



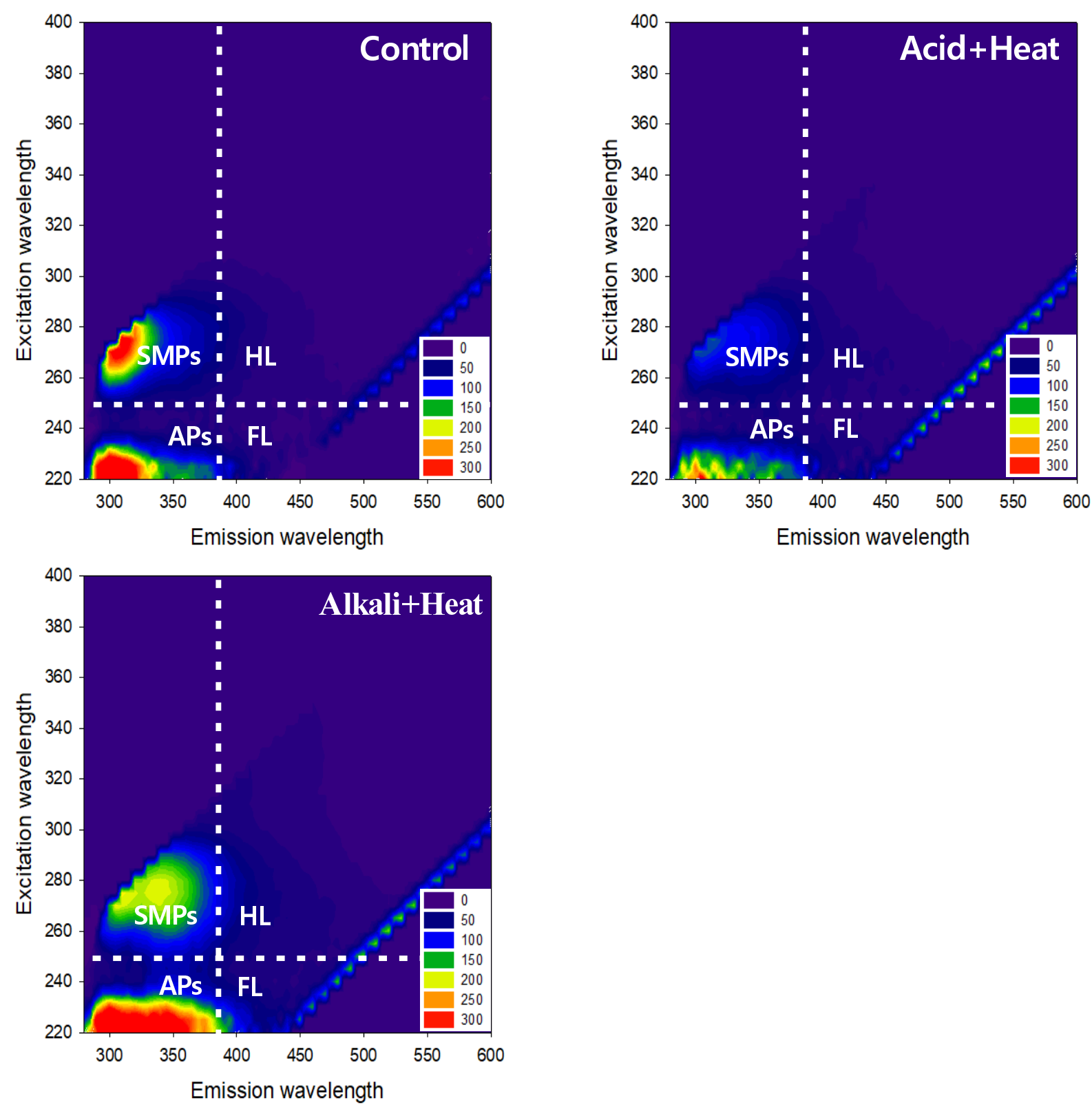

Fig. 2. FEEM spectra of dissolved organic matters of pretreated waste activated sludge.

로 하여 화학물질 주입량을 최소화 했음에도 불구하고 Acid+ Heat에 비해 낮은 메탄수율이 측정되었으며 그 원인에 대하여 Chapter 3.3.에서 보다 구체적으로 서술하였다.

\section{3. 용존성 물질의 성상 분석}

전처리 적용에 따른 가용화율은 비슷하나 생산된 메탄 발생 량의 차이의 원인을 파악하기 위해 추가적으로 전처리 적용 시 가용화된 용존성 물질의 성상 분석을 진행했다. 용존성 물질 의 성상 변화 파악을 위해 FEEM 및 분자량 분석을 진행했으며 그 결과는 Figs. 2,3에 나타냈다. EEM peak는 4개의 영역으로 구분되며 Soluble microbial products(SMPs)의 경우 미생물의 부산물로 세포벽, Extracellular polymeric substances(EPS) 등
분해가 쉽지 않은 물질을 포함하며 Aromatic compounds(APs) 는 방향족 구조를 갖는 물질로 SMPs와 마찬가지로 분해가 어려운 물질을 포함한다. ${ }^{22)}$ Humic-like(HL)과 Fulvic-like(FL) 은 각각 '휴믹산과 유사한 물질', ‘풀빅산과 유사한 물질'을 뜻한다. 각각의 영역이 적색에 가까울수록 그 강도가 높음을 나타내고 높은 강도는 용존성 물질 내에 해당물질의 농도가 높음을 의미한다. ${ }^{23,24)}$ 대조군의 경우 SMPs와 APs에서 높은 강도를 보였으나 전처리를 적용한 결과 두 물질의 강도 변화가 뚜렷하게 나타났다. Acid+Heat 샘플에서는 SMPs와 APs 두 영역에서의 강도가 현저히 감소된 것으로 나타났다. 반면에 Alkali+Heat 샘플에서는 SMPs 강도의 감소를 보이나 Acid+Heat 샘플과 비교하여 여전히 높은 강도를 보였으며 오히 


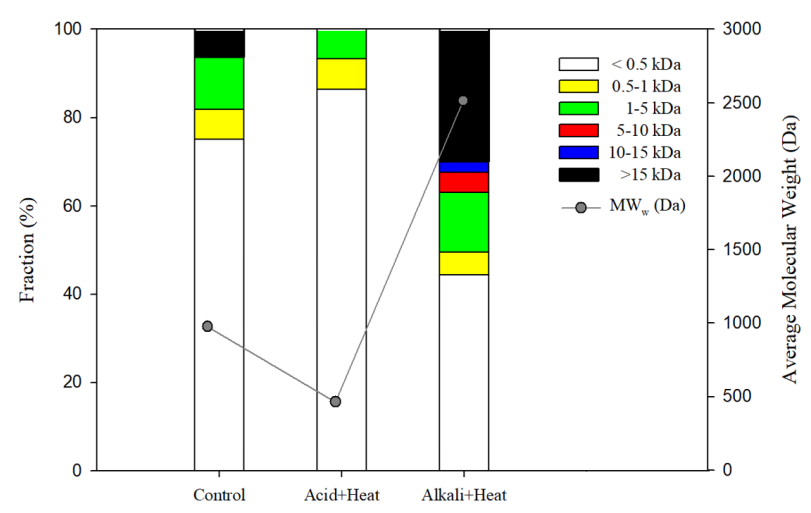

Fig. 3. Results of HPLC/SEC-FLD analyses of pretreated waste activated sludge.

려 APs 영역의 범위가 커진 것으로 나타났다. 모든 샘플에서는 $\mathrm{HL}$ 과 $\mathrm{FL}$ 의 강도는 무시할 정도의 수준으로 약하게 나타났다.

$\mathrm{EEM}$ 분석 결과를 통해 미생물 cell로 이루어진 잉여찌꺼기 가 전처리에 의해 가용화 과정에서 미생물의 세포벽 및 구성물 질들의 파괴가 일어났으며 전처리 방법에 따른 그 차이가 발생 한 것으로 해석된다. 특히, Acid+Heat 전처리에 의해 잉여찌꺼 기가 가용화된 용존성 물질은 SMPs와 APs 계열의 물질의 함 량이 적었고 Alkali+Heat 전처리에 의해 높은 농도의 SMPs 및 APs가 용존성 물질에 포함하고 있는 것으로 나타났다.

전처리 적용에 따른 평균분자량 및 분자량 분포 결과를 Table1과 Fig.3에 나타냈다. 대조군의 경우 $976 \mathrm{Da}$ 로 나타났 으며 Acid+Heat 샘플은 $463 \mathrm{Da}$ 로 $53 \%$ 감소를 보였다. 반면에 Alkali+Heat 샘플의 경우 $258 \%$ 증가한 $2,514 \mathrm{Da}$ 의 결과를 보 였다. 대조군에서의 분자량 분포의 경우 $75 \%$ 가 $0.5 \mathrm{kDa}$ 이하 의 낮은 분자량 물질로 구성되어 있으며 $15 \mathrm{kDa}$ 이상의 높은 분자량을 갖는 물질을 $6 \%$ 내외로 포함하고 있음을 볼 수 있 다. Acid+Heat 샘플의 경우 $0.5 \mathrm{kDa}$ 이하인 물질이 약 $86 \%$ 이며 $15 \mathrm{kDa}$ 이상인 물질은 존재하지 않았다. Alkali+Heat 샘 플의 경우 $0.5 \mathrm{kDa}$ 이하의 물질이 $44 \%$ 존재하며 $15 \mathrm{kDa}$ 이상 인 물질이 $30 \%$ 존재함을 볼 수 있다. 위 결과를 통해 Acid+ Heat 전처리를 통해 전환된 용존성 물질은 고분자 물질들이 대부분 저분자 형태 $(0.5 \mathrm{kDa}$ 이하)로 전환되었다고 파악된다. 반면, Alkali+Heat 전처리에 의해 전환된 용존성 물질은 상대 적으로 $15 \mathrm{kDa}$ 이상의 고분자 물질이 포함되었으며 이는 Acid+Heat 전처리와 비교하여 전처리 효과 및 메커니즘의 차 이에 의한 결과로 판단된다.

전처리 적용에 따른 가용화된 용존 물질의 성상 파악을 위해 수행한 EEM 분석 및 분자량 분포 분석 결과로부터 전처리 적용 및 방법에 따른 용존성 물질의 성상 변화를 보다 명확하게 확인할 수 있었다. Acid+Heat 전처리를 통해 전환된 용존성 물질의 경우 대부분 저분자 형태로 존재했으며 SMPs, APs 물질의 함량이 적은 것으로 나타났다. 반면에 Alkali+Heat 전처 리를 적용한 샘플은 용존성 물질 내 상대적으로 $\mathrm{SMPs}, \mathrm{APs}$ 와
같은 난분해성 고분자 형태의 물질의 높은 함량 분포를 보였다. 따라서 Acid+Heat과 Alkali+Heat 전처리 적용 시 이들 샘플 의 가용화율의 결과가 비슷하다 하더라도 두 전처리의 메커니 즘과 그 효율의 차이에 따라 용존성 물질의 성상 및 분포 차이 가 발생하며 최종적으로 이들의 메탄 전환율의 차이의 결과로 이어진 것으로 판단된다. 특히, Acid+Heat 전처리의 경우 용 존성 물질 내 저분자 물질의 분포가 증가하여 상대적으로 높 은 메탄 전환율의 결과로 이어졌으며 Alkali+Heat의 경우 용 존물질 내 난분해성 고분자 형태의 물질의 높은 함량에 의해 메탄 전환율의 증가 폭이 상대적으로 낮게 나타났던 것으로 해석된다.

\section{4. 결론}

본 연구는 하수잉여찌꺼기의 병합 전처리 적용방법(Acid+ Heat 및 Alkali+Heat)에 따른 가용화와 메탄 생산량의 관계를 파악하고 그 차이에 대한 원인 규명을 목적으로 수행되었다. 실험 결과 Alkali+Heat 처리의 가용화율이 더 높으나 메탄수 율 측면에선 Acid+Heat이 더 효과적이라는 것을 확인했다. 연 구 결과 원인 규명을 위해 FEEM 분석 수행 결과 Acid+Heat 적용 시 대조군에 비해 SMPs 및 $\mathrm{APs}$ 의 함량이 감소되었음을 확인할 수 있으나 Alkali+Heat 적용 시엔 SMPs 및 APs의 함 량이 오히려 증가했음을 확인했다. Acid+Heat의 평균 분자량 은 대조군의 평균 분자량 $(976 \mathrm{Da})$ 에 비해 더 낮은 $463 \mathrm{Da}$ 로 측정되었으며 Alkali+Heat의 평균 분자량은 더 높은 $2,514 \mathrm{Da}$ 으로 나타났다. 본 결과를 통해 전처리를 적용할 경우 고형유 기물질이 대부분 생물학적 메탄 전환에 용이한 저분자 형태의 용존 유기물로 전환되었음을 확인했으며 반면 Alkali+Heat 전 처리를 적용할 경우 고형 유기물질들이 가용화 되는 과정에서 고분자 형태의 용존 유기물로 존재하여 미생물의 메탄생산 효율이 떨어짐을 확인했다. 본 연구 결과는 가용화율은 메탄 생산성과 연계할 수 있는 전처리 효과로 판단하는 절대 지표 가 아니라는 것을 의미하며 전처리 방법에 따른 용존 유기물 의 특성이 다르다는 것을 의미한다.

\section{Acknowledgments}

This work was supported by the National Research Foundation of Korea(NRF) grant funded by the Korea Government(MSIT) (No.NRF2018R1C1B6003091) and the Korea Ministry of Environment as Waste to Energy-Recycling Human Resource Development Project(YL-WE-19-002).

\section{References}

1. Ministry of environment, Sewerage statistics(2019).

2. Ministry of environment, Basic plan for energy 
independence(2010).

3. W. Gujer, A. J. Zehnder, Conversion processes in anaerobic digestion, Water Sci. Technol., 15(8-9), 127-167(1983).

4. F. Markis, J. C. Baudez, R. Parthasarathy, P. Slatter, N. Eshtiaghi, Rheological characterisation of primary and secondary sludge: Impact of solids concentration, Chem. Eng. J., 253, 526-537(2014).

5. T. Noike, G. Endo, J. E. Chang, J. I. Yaguchi, J. I. Matsumoto, Characteristics of carbohydrate degradation and the rate limiting step in anaerobic digestion, Biotechnol. bioeng., 27(10), 1482-1489(1985).

6. R. Y. Kannah, S. Kavitha, J. R. Banu, I. T. Yeom, M. J. B. T. Johnson, Synergetic effect of combined pretreatment for energy efficient biogas generation, Bioresour. Technol., 232, 235-246(2017).

7. G. Zhen, X. Lu, H. Kato, Y. Zhao, Y. Y. Li, Overview of pretreatment strategies for enhancing sewage sludge disintegration and subsequent anaerobic digestion: Current advances, full-scale application and future perspectives, Renewable Sustainable Energy Rev., 69, 559-577(2017).

8. Y. Chen, M. A. Stevens, Y. Zhu, J. Holmes, H. Xu, Understanding of alkaline pretreatment parameters for corn stover enzymatic saccharification, Biotechnol. Biofuels, 6(1), 1-10(2013).

9. S. Şahinkaya, M. F. Sevimli, Sono-thermal pre-treatment of waste activated sludge before anaerobic digestion, Ultrason. Sonochem., 20(1), 587-594(2013).

10. D. C. Devlin, S. R. R. Esteves, R. M. Dinsdale, A. J. Guwy, The effect of acid pretreatment on the anaerobic digestion and dewatering of waste activated sludge, Bioresour. Technol., 102(5), 4076-4082(2011).

11. A. Valo, H. Carrère, J. P. Delgenès, Thermal, chemical and thermo chemical pre treatment of waste activated sludge for anaerobic digestion, JJ. Chem. Technol. Biotechnol., 79(11), 1197-1203(2004).

12. S. Hasegawa, N. Shiota, K. Katsura, A. Akashi, Solubilization of organic sludge by thermophilic aerobic bacteria as a pretreatment for anaerobic digestion, Water Sci. Technol., 41(3), 163-169(2000).

13. A. G. Vlyssides, P. K. Karlis, Thermal-alkaline solubilization of waste activated sludge as a pre-treatment stage for anaerobic digestion, Bioresour. Technol., 91(2), 201-206(2004).

14. C. Bougrier, C. Albasi, J. P. Delgenès, H. Carrère, Effect of ultrasonic, thermal and ozone pre-treatments on waste activated sludge solubilisation and anaerobic biodegradability, Chem. Eng. Process, 45(8), 711-718(2006).

15. M. Climent, I. Ferrer, M. del Mar Baeza, A. Artola, F. Vázquez, $\mathrm{X}$. Font, Effects of thermal and mechanical pretreatments of secondary sludge on biogas production under thermophilic conditions, Chem. Eng. J, 133(1-3), 335-342(2007).

16. N. D. Park, S. S. Helle, R. W. Thring, Combined alkaline and ultrasound pre-treatment of thickened pulp mill waste activated sludge for improved anaerobic digestion, Biomass Bioenergy, 46, 750-756(2012).

17. D. H. Kim, S. K. Cho, M. K. Lee, M. S. Kim, Increased solubilization of excess sludge does not always result in enhanced anaerobic digestion efficiency, Bioresour. Technol., 143, 660-664(2013).

18. W. E. Federation, APH Association, Standard methods for the examination of water and wastewater, American Public Health Association(APHA): Washington, DC, USA(2005).

19. J. J. Lay, Y. J. Lee, T. Noike, Feasibility of biological hydrogen production from organic fraction of municipal solid waste, Water Res., 33(11), 2579-2586(1999).

20. P. Neumann, Z. González, G. Vidal, Sequential ultrasound and low-temperature thermal pretreatment: process optimization and influence on sewage sludge solubilization, enzyme activity and anaerobic digestion, Bioresour. Technol., 234, 178-187(2017).

21. D-J. Kim, Pre-treatment Technology of Wastewater Sludge for Enhanced Biogas Production in Anaerobic Digestion, Clean Technol., 19(4), 355-369(2013).

22. D. Zhang, Y. Zhou, T. V. Bugge, B. Mayanti, A. Yang, L. S. Poh, ... W. J. Ng, Soluble microbial products(SMPs) in a sequencing batch reactor with novel cake filtration system, Chemosphere, 184, 1286-1297(2017).

23. Y. M. Yun, M. Kim, H. Kim, D. H. Kim, E. E. Kwon, S. Kang, Increased biodegradability of low-grade coal wastewater in anaerobic membrane bioreactor by adding yeast wastes, J. Environ. Manage., 234, 36-43(2019).

24. X. Li, X. Dai, J. Takahashi, N. Li, J. Jin, L. Dai, B. Dong, New insight into chemical changes of dissolved organic matter during anaerobic digestion of dewatered sewage sludge using EEM-PARAFAC and two-dimensional FTIR correlation spectroscopy, Bioresour. Technol., 159, 412-420(2014).

\section{Declaration of Competing Interest}

The authors declare that they have no known competing financial interests or personal relationships that could have appeared to influence the work reported in this paper.

\section{Authors and Contribution Statement}

\section{Byung-Kyu Ahn}

Department of Environmental Engineering, Chungbuk National University, master's course ORCID (10 0000-0003-4379-785X: Data curation, Data analysis, Visualization, Writing - Original Draft.

\section{Tae-Hoon Kim}

Department of Environmental Engineering, Chungbuk National University, Ph.D. Candidate, ORCID(D) 0000-0003-1240-4662: Data curation, Data analysis

\section{Hyojeon Kim}

Department of Civil and Environmental Engineering, KAIST, Ph.D, ORCiD(0) 0000-0001-5949-5800: Data curation, Data analysis 
Byung-Kyu Ahn et al.

\section{Seoktae Kang}

Department of Civil and Environmental Engineering, KAIST, Professor, ORCID (이 0000-0002-5113-3992: Data curation, Data

\section{Yeo-Myeong Yun}

Department of Environmental Engineering, Chungbuk National University, Assistant Professor, ORCID (1) 0000-0002-8117-4306: Conceptualization, Data analysis, Methodology, Visualization, Writing - review and editing, Funding acquisition, Project administration, Resources, Supervision, Validation, Visualization. 